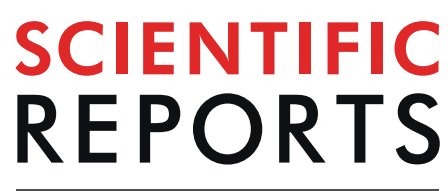

natureresearch

Check for updates

\title{
A new ingestion bioassay protocol for assessing pesticide toxicity to the adult Japanese orchard bee (Osmia cornifrons)
}

NgocT. Phan ${ }^{1,2 凶}$, Neelendra K. Joshi ${ }^{3}$, Edwin G. Rajotte $^{1}{ }^{1}$ Margarita M. López-Uribe ${ }^{1}$, Fang Zhu ${ }^{1}$ \& David J. Biddinger ${ }^{1,4} \bowtie$

Adopting an Integrated Pest and Pollinator Management strategy requires an evaluation of pesticide risk for pollinator species. For non-Apid species, however, the standardized ingestion assays are difficult to implement. This hinders the consideration of non-Apid species in farm management strategies and government regulatory processes. We describe a new method for a mason bee, Osmia cornifrons, which is an important pollinator of apples and other fruit crops. Our approach overcomes high control mortality seen in other bioassay protocols and expands testing to include males as well as females. The new pesticide toxicity assessment protocol showed that (1) a group feeding method is optimum even though there is no trophallaxis, (2) males had better tolerance to pesticides although they are smaller, and (3) pesticides can cause additional mortality after the standard $48 \mathrm{~h}$ assessment time specified by European Food Safety Authority and U.S. Environmental Protection Agency.

The global decline of pollinator populations has led to the need to develop an Integrated Pest and Pollinator Management (IPPM) framework that balances optimal pest control while ensuring pollinator health in agroecosystems ${ }^{1}$. Among multiple biotic and abiotic factors leading to pollinator decline, a major threat bees face while pollinating crops is the exposure to various insecticides, fungicides, herbicides, and even some plant growth regulators, which are applied to crops via foliar sprays, soil applications or seed treatments ${ }^{2-4}$. There are two main routes of pesticide exposure for foraging bees, contact with sprayed plant parts and ingestion with pollen and nectar ${ }^{2}$. Pollen and nectar can acquire pesticides applied via foliar applications applied pre-boom that translocate systemically through the plant vascular system into the nectar and pollen when flowers open ${ }^{5-7}$. Some pesticides applied during bloom can lead to contact exposure of pollinating insects ${ }^{8,9}$.

Honey bees (Apis mellifera) and bumble bees (Bombus spp.), both Apids, are the two taxa most frequently tested in bioassays that assess the risk and toxicity of pesticides to bee pollinators. Moreover, only female bees have been tested because males of these species are less abundant and much less important pollinators. Standardized test methodologies for assessing pesticide toxicity through contact and ingestion have been developed for these social species, but these methods cannot be utilized on non-social bees because of differences in behavior and rearing requirements ${ }^{4,10,11}$. Bees comprise a group of over 20,000 species that widely vary in physiology, ecology and behavior - about $70 \%$ of all species are solitary. The need for more robust protocols for pesticide risk assessment of pollinators has led to a high demand for the development of bioassays on solitary bee species ${ }^{1,12}$.

The Japanese orchard bee, Osmia cornifrons Radoszkowski (Hymenoptera: Megachilidae), is a solitary mason bee that is now managed as an alternative pollinator for the tree fruit industry ${ }^{13-15}$. Osmia cornifrons has been used to pollinate fruit orchards in Japan since the 1930s and was introduced to the U.S. in the 1970s by the U.S. Department of Agriculture (USDA) for this purpose ${ }^{13,16}$. The bees emerge from tubular nests (either manmade tubes or natural cavities in trees) as adults ready to forage in early spring when honey bee colonies have not yet reached their optimum strength and population size to pollinate crops in temperate climates ${ }^{17,18}$. Osmia cornifrons are short-ranged pollinators with a typical foraging range of $40-60 \mathrm{~m}$ and tend to stay in the orchards rather than

${ }^{1}$ Department of Entomology, The Pennsylvania State University, University Park, PA, USA. ${ }^{2}$ Research Center for Tropical Bees and Beekeeping, Vietnam National University of Agriculture, Hanoi, Vietnam. ${ }^{3}$ Department of Entomology and Plant Pathology, University of Arkansas, Fayetteville, AR, USA. ${ }^{4}$ Penn State Fruit Research and

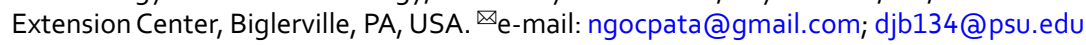




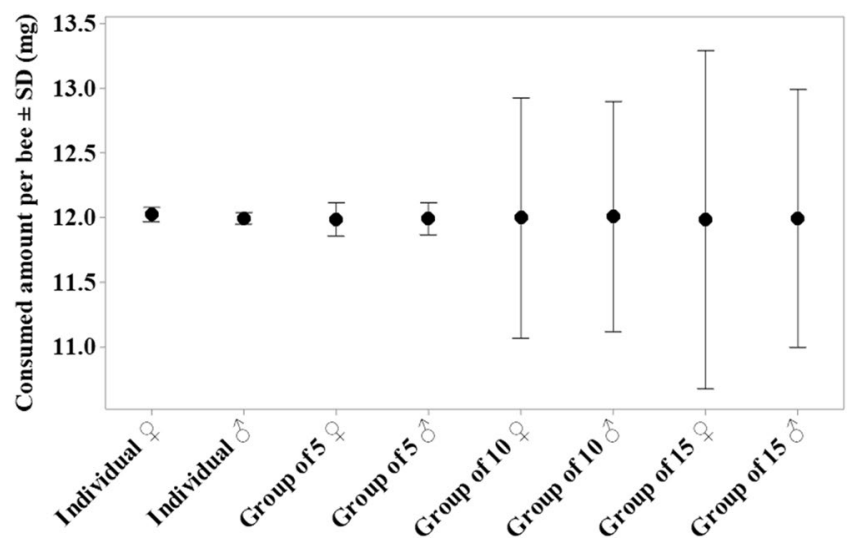

Figure 1. Consumed solution amount per adult Osmia cornifrons (in mg) for different feeding group sizes: individual feeding vs. group feeding (group of 5, group of 10, and group of 15 bees per container, respectively). Interval plot was created by Minitab 19; Dots show the mean and the error bars show standard deviations; Data table and further analysis can be found in the Supplementary Materials (Fig. S1 and Table S1).

flying among different crops or non-crop hosts like honey bees ${ }^{13,19,20}$. Osmia spp. are relatively easy to manage; the adults fly for only a few weeks of the year and once the adult flight period is over, completed nest tubes with larvae developing on pollen provisions can be removed from the field and stored until the next pollination season with minimal labor or costs for specialized beekeeping equipment ${ }^{21,22}$.

Bioassays to assess contact toxicity of systemic pesticides on adult Osmia have been performed, but bees are also exposed to systemic pesticides through ingestion ${ }^{12}$. Various adult ingestion methods have been attempted on the related red mason bee, O. bicornis (L.), and the European orchard bee, O. cornuta (Latreille) (mainly adapted from methods for honeybees and bumble bees), including group feeding and individual feeding methods such as the film canister method, glass vial method, and flower method ${ }^{23-27}$. Several experiments were conducted based on the European Food Safety Authority (EFSA) guidance document on pollinator risk assessment of pesticides. However, the success rates for these methods for adult solitary bee testing are very low due to high mortality, even in control groups. Indeed, based on the summary presentation of the International Commission of Plant-Pollinator Relationships (ICP-PR) non-Apis workshop 2017 (Valencia, Spain), the mortality rate in control treatment groups exceeded $20 \%{ }^{28}$. Another potential problem is the time of mortality assessment. Presently, the U.S. Environmental Protection Agency (EPA) and EFSA regulations require mortality assessments at $48 \mathrm{~h}$ and $96 \mathrm{~h}$, respectively ${ }^{10,11}$, but longer time periods may be necessary to capture delayed mortality.

All of the acute toxicity bioassays on Osmia spp. that have been conducted to date, involving both topical treatments and ingestion, have been done only on the females ${ }^{12,29-31}$. We evaluated the susceptibility of both females and males, not only because both take part in pollination processes and are exposed to orchard chemicals, but also because unlike social species where only a few males are needed to produce thousands of female worker offspring, sex ratios approaching 1:1 are typical in solitary bees. Without males, unmated female Osmia bees will only produce female-sized sons ${ }^{32,33}$ reducing the number of bees available for pollination. Bodyweight differences between males and females also need to be considered. Smaller individuals, males in Osmia species, tend to be more severely affected than larger bees when exposed to the same amount of a toxic substance ${ }^{34}$.

In this study, we (1) developed a standard protocol for ingestion toxicity assessment for non-Apid bees, using O. cornifrons as an exemplar; (2) examined the toxicity to both males and females of common pesticides applied to commercial apple trees; and (3) determined the optimal time after pesticide exposure to evaluate toxicity for ingested pesticides.

\section{Results}

Development of ingestion bioassay protocol. Optimal feeding method. The best method for this bioassay was feeding O. cornifrons in groups of five (Fig. 1). In this grouping, bees started feeding earlier and consumed all of the available food within the assigned four hours. This group feeding also allowed the even distribution of food (and dosing) among individuals during the assay (Levene's test; Fig. S1 and Table S1). In contrast, when fed individually, bees took up to 48 hours to finish imbibing the solution. Moreover, bees tested individually delayed food ingestion; males delayed feeding for 12 hours and females for 24 hours (NP personal observation). For other group feeding methods (group sizes of 10 and 15 bees), there was obvious competition among the bees: some bees consumed greater amounts while the others consumed less than the average assigned food ( $10 \mathrm{uL}$ of $50 \% \mathrm{~W}: \mathrm{W}$ sucrose solution, which weighed $12 \mathrm{mg}$; Fig. S1 and Table S1).

Ingestion bioassay protocol. We repeated the O. cornifrons adult ingestion bioassay over two seasons (spring 2016 and spring 2017) using bees from the same source representing the same weight range (100-110 $\mathrm{mg}$ for females, $65-75 \mathrm{mg}$ for males) and testing the same pesticide formulations (Table S2) in order to validate the group feeding method. A key point of this ingestion bioassay was to get the O. cornifrons to accept the feeders. We utilized two different feeding stimulation techniques. For the first year, we painted each feeding hole in the $2 \mathrm{~mL}$ feeder tubes with a red Sharpie Permanent Marker. The red Sharpie was effective in stimulating the bees to feed. We do not 


\begin{tabular}{|c|c|c|c|c|c|}
\hline $\begin{array}{l}\text { Active } \\
\text { ingredient }^{1}\end{array}$ & Sex & Year & $\mathbf{N}^{\ddagger}$ & $\begin{array}{l}\mathrm{LD}_{50} \text { (ng AI/mg } \\
\text { bodyweight) } \\
\text { (95\% CL) }\end{array}$ & $\begin{array}{l}\mathrm{LD}_{50} \text { ratio } \\
\text { (95\% limits) }\end{array}$ \\
\hline \multirow{4}{*}{ Thiamethoxam } & \multirow{2}{*}{ ф } & 2016 & 225 & $\begin{array}{l}0.034 \\
(0.005-0.059)\end{array}$ & \multirow{2}{*}{$\begin{array}{l}1.11 \\
(0.35-1.17)\end{array}$} \\
\hline & & 2017 & 225 & $\begin{array}{l}0.030 \\
(0.013-0.050)\end{array}$ & \\
\hline & \multirow{2}{*}{ 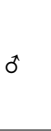 } & 2016 & 225 & $\begin{array}{l}0.011 \\
(0.001-0.030)\end{array}$ & \multirow{2}{*}{$\begin{array}{l}1.55 \\
(0.69-1.90)\end{array}$} \\
\hline & & 2017 & 225 & $\begin{array}{l}0.007 \\
(0.001-0.016)\end{array}$ & \\
\hline \multirow{4}{*}{ Imidacloprid } & \multirow{2}{*}{ } & 2016 & 225 & $\begin{array}{l}0.013 \\
(0.009-0.028)\end{array}$ & \multirow{2}{*}{$\begin{array}{l}0.77 \\
(0.58-1.45)\end{array}$} \\
\hline & & 2017 & 250 & $\begin{array}{l}0.017 \\
(0.016-0.019)\end{array}$ & \\
\hline & \multirow{2}{*}{ 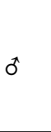 } & 2016 & 225 & $\begin{array}{l}0.042 \\
(0.019-0.057)\end{array}$ & \multirow{2}{*}{$\begin{array}{l}1.25 \\
(0.65-1.52)\end{array}$} \\
\hline & & 2017 & 250 & $\begin{array}{l}0.033 \\
(0.029-0.038)\end{array}$ & \\
\hline \multirow{4}{*}{ Acetamiprid } & \multirow{2}{*}{ 우 } & 2016 & 225 & $\begin{array}{l}0.14 \\
(0.06-0.23)\end{array}$ & \multirow{2}{*}{$\begin{array}{l}1.25 \\
(0.86-1.33)\end{array}$} \\
\hline & & 2017 & 270 & $\begin{array}{l}0.11 \\
(0.07-0.17)\end{array}$ & \\
\hline & \multirow{2}{*}{0} & 2016 & 225 & $\begin{array}{l}0.55 \\
(0.32-1.09)\end{array}$ & \multirow{2}{*}{$\begin{array}{l}0.93 \\
(0.60-1.52)\end{array}$} \\
\hline & & 2017 & 270 & $\begin{array}{l}0.59 \\
(0.50-0.69)\end{array}$ & \\
\hline
\end{tabular}

Table 1. Comparison of toxicity responses of adult Osmia cornifrons to various pesticides through ingestion bioassays (at 7 days after treatment) conducted over two years $(2016,2017) .{ }^{1}$ The product formulations are listed in Table S2. ${ }^{*} \mathrm{~N}$ is the number of individuals tested for each product. $\mathrm{LD}_{50}$ ratio in this table, or ratio of doses causing $50 \%$ mortality, is $\mathrm{LD}_{50}$ in $2016 \div \mathrm{LD}_{50}$ in 2017 . The bioassay result can be considered the same when the $\mathrm{LD}_{50}$ ratio is not significantly different from $1.0^{46}$. All $95 \%$ limits of $\mathrm{LD}_{50}$ ratios do overlap and include the value 1.0 , indicating the response was similar in both years and validate the reproducibility of our protocol. Products are listed in decreasing order, from the most to the least toxic (based on quantal response bioassay results from POLOPlus 2.0).

know why it was a stimulus; whether it was a visual cue or an olfactory cue can be assessed in a future experiment. For the second year, we used smears of honey on the $2 \mathrm{~mL}$ feeder tubes, which was better than the red Sharpie because it reduced handling time and also stimulated feeding. Instead of having to paint each feeder hole with the marker pen, we could easily use a honey-dampened Q-tip and swipe all of the feeder holes at once. In the second year (2017), we narrowed the pesticide concentrations to those more likely to cause 5-95\% mortality in the test population, thus $95 \% \mathrm{CL}$ of the $\mathrm{LD}_{50} \mathrm{~s}$ (at 7 days after treatment) in 2017 were narrower than in 2016 (Table 1). The results of the two seasons were similar with $0 \%$ control mortality in both years indicating that our ingestion bioassay protocol for $O$. cornifrons was reproducible and the group feeding method was reliable for pesticide toxicity testing. The change in the stimulation feeding technique was an improvement and did not affect the final results.

Sex-based differences in toxicity responses of Osmia cornifrons adults. Our data indicated over the two years that the females were more susceptible than the males for imidacloprid and acetamiprid (Table 2). No difference in response was recorded in the treatment containing thiamethoxam (Table 2). Again, the similarity of experiment results between the two years showed that our ingestion bioassay protocol was reliable.

Delayed mortality assessment. Mortality of $O$. cornifrons varied over time in this study, requiring that each pesticide be evaluated at different intervals after exposure. Male mortality did not increase significantly at the $\mathrm{LD}_{50}$ level for imidacloprid after the $48 \mathrm{~h}$ mortality readings (Table 3 ). In contrast, thiamethoxam and acetamiprid continued to cause additional mortality in both sexes until the $7 \mathrm{~d}$ assessment. Table 3 presents the mortality of $O$. cornifrons (2017) at different times post-treatment (2 days, 5 days, and 7 days) in different pesticide treatments. The result of 2016 was excluded because of its similarity with the result of 2017 . It can be found in Supplementary Materials (Table S3).

\section{Discussion}

We developed a robust and reproducible laboratory procedure to examine pesticide toxicity by ingestion in the solitary mason bee $O$. cornifrons. The consumption test showed that a cohort of five bees was the optimal number of bees per container for the ingestion bioassays even though O. cornifrons do not perform trophallaxis. Utilizing this procedure, toxicity responses of $O$. cornifrons to common orchard neonicotinoids revealed sex-differential responses, which showed that females are more susceptible than males (even when body mass was accounted for) for most of the pesticides examined. Since males in solitary bees are important for crop pollination ${ }^{18,35}$, 


\begin{tabular}{|c|c|c|c|c|}
\hline Active ingredient ${ }^{1}$ & Year & Sex & $\mathbf{N}^{\ddagger}$ & $\begin{array}{l}\text { Sensitivity } \\
\text { ratio (95\% limits) }\end{array}$ \\
\hline \multirow{4}{*}{ Thiamethoxam ${ }^{\S}$} & \multirow{2}{*}{2016} & $q$ & 225 & \multirow{2}{*}{$\begin{array}{l}1.9 \\
(0.95-2.85)\end{array}$} \\
\hline & & $0^{*}$ & 225 & \\
\hline & \multirow{2}{*}{2017} & 9 & 225 & \multirow{2}{*}{$\begin{array}{l}2.38 \\
(0.95-2.85)\end{array}$} \\
\hline & & 0 & 225 & \\
\hline \multirow{4}{*}{ Imidacloprid } & \multirow{2}{*}{2016} & & 225 & \multirow{2}{*}{$\begin{array}{l}0.32^{*} \\
(0.47-0.51)\end{array}$} \\
\hline & & $0^{\pi}$ & 225 & \\
\hline & \multirow{2}{*}{2017} & q & 250 & \multirow{2}{*}{$\begin{array}{l}0.48^{*} \\
(0.32-0.67)\end{array}$} \\
\hline & & o & 250 & \\
\hline \multirow{4}{*}{ Acetamiprid } & \multirow{2}{*}{2016} & $q$ & 225 & \multirow{2}{*}{$\begin{array}{l}0.19^{*} \\
(0.13-0.26)\end{array}$} \\
\hline & & $0^{+}$ & 225 & \\
\hline & \multirow{2}{*}{2017} & q & 270 & \multirow{2}{*}{$\begin{array}{l}0.20 * \\
(0.13-0.26)\end{array}$} \\
\hline & & 0 & 270 & \\
\hline
\end{tabular}

Table 2. Sex-based differences in toxicity responses of Osmia cornifrons adults to various pesticides at 7 days after pesticide treatment. ${ }^{1}$ The product formulations are listed in Table S2. ${ }^{\ddagger} \mathrm{N}$ is the number of individuals tested for each chemical. Sensitivity ratio, or lethal dose ratio at $50 \%$ mortality reading, is $\mathrm{LD}_{50}$ of female $\div \mathrm{LD}_{50}$ of male. Females are significantly $(*)$ more susceptible than males to a product when the following requirements are met: (1) sensitivity ratio $<1.0$, and (2) $95 \%$ limit of sensitivity ratio does not include the value $1.0^{46}$. Otherwise, females and males can be considered to have the same response to a product. Control mortality was $0 \%$. Products are listed in decreasing order, from the most to the least toxic (based on quantal response bioassay results from POLO Plus 2.0). *Significant at the $95 \%$ confidence level. ${ }^{\S}$ No difference in sex response.

pesticide impacts should be assessed for both sexes separately but females should have priority because of their higher susceptibility to pesticides. The reason for such sex-based differences in pesticide sensitivity or detoxification warrants further study ${ }^{36}$. Delayed mortality responses in O. cornifrons varied significantly across different pesticide active ingredients, with adult mortality reaching a maximum anywhere from 48 hours up to 7 days post-treatment. Presently, the EPA and EFSA regulations require assessment at $48 \mathrm{~h}$ and $96 \mathrm{~h}$, respectively ${ }^{10,11}$. Based on our two-year study, we suggest that the mortality assessment protocols of these pesticide regulations should be revised.

Our results also contribute to the increasing evidence that the toxicity responses and detoxification mechanisms significantly vary across different bee families ${ }^{12,37,38}$. Future research should include comparing the susceptibility to pesticides to representatives of all bee families that significantly contribute to crop pollination including other members of the families Apidae, Megachilidae, Andrenidae and Halictidae. Pesticide risk assessments should not be based only on the responses of honey bees or bumble bees in cropping systems where significant pollination is being carried out by solitary bees ${ }^{16,39-41}$. We, and many others, question whether it is appropriate for pesticide policy to be made testing only honey bees that have vastly different behavioral, physiological and ecological traits compared to most other bee species ${ }^{40}$. Developing pesticide testing protocols for alternative pollinators is a step forward in understanding pesticide impacts on the majority of bee species.

We recommend group feeding in a cohort of five for O. cornifrons in future ingestion toxicity tests as this will ensure the bees consume the assigned amount within 4 hours of exposure. A series of pretests with different types of containers and different feeding stimulation techniques should be made to tailor the method for other species of solitary bees even within the same genus, as pre-trials with O. lignaria Say demonstrated much different feeding and foraging behaviors than $O$. cornifrons (NP and DB personal observation). We also recommend sex-based pesticide toxicity testing because male solitary bees also take part in pollination, are important for reproduction ${ }^{35,42-44}$, and can be the more-susceptible sex. Finally, we suggest that mortality assessment in pesticide toxicity tests should be extended beyond the current 48 hours to at least 7 days after treatment to ascertain the full mortality.

\section{Methods}

Collection and handling of the Osmia cornifrons for lab bioassays. Osmia cornifrons used for all bioassays were sourced from a single supplier (S. Famous, Harleysville, PA). Wild populations were trap nested in the supplier's suburban backyard and from a nearby unsprayed park to minimize previous pesticide exposure prior to the bioassays. Both locations are at least $1,000 \mathrm{~m}$ from the nearest farm and isolated from agricultural pesticides. Binderboards (Pollinator Paradise, Parma, ID) type of mason bee trap nests, consisting of laminated wooden rearing blocks with $8 \mathrm{~mm}$-diameter holes lined with paper straws, were used. Adult emergence, pollen provisions, and egg-laying took place over several weeks starting in April and continuing through the first week of May in 2015 and 2016. Over the winter, straws containing the completed cocoons were stored in a screened insectary under ambient temperatures and protected from direct sunlight, rain, and snow.

In both years, the bees were received from the supplier in the winter as nest straws (extracted from nest tubes) containing adults in cocoons. The straws were processed, stored and prepared for release at the Penn State Fruit Research Center, Biglerville, PA as follows: The nest straws were peeled open to release the cocoons, which were then washed under running cold tap water to clean off kleptoparasitic pollen mites (Chaetodactylus sp., Acari: Chaetodactylidae), larval frass, pollen store remnants, and pieces of the mud partitions between cells. The damp cocoons were then air-dried at $20^{\circ} \mathrm{C}$ for about 30 minutes on paper towels and stored at $2{ }^{\circ} \mathrm{C}$ to simulate winter 


\begin{tabular}{|c|c|c|c|c|c|c|}
\hline $\begin{array}{l}\text { Active } \\
\text { ingredient }^{1}\end{array}$ & Sex & $\mathbf{N}$ & $\begin{array}{l}\text { Time of mortality } \\
\text { reading }{ }^{\mathrm{a}}\end{array}$ & Slope \pm SE & $\begin{array}{l}\mathrm{LD}_{50} \text { (ng AI/mg } \\
\text { bodyweight) } \\
\text { (95\% CL) }\end{array}$ & $\begin{array}{l}\mathrm{LD}_{50} \text { ratio } \\
\text { (95\% limits) }\end{array}$ \\
\hline \multirow{6}{*}{ Thiamethoxam } & \multirow{3}{*}{ \% } & \multirow{3}{*}{225} & 2 & $1.68 \pm 0.20$ & $\begin{array}{l}0.077 \\
(0.048-0.114)\end{array}$ & \\
\hline & & & 5 & $1.53 \pm 0.20$ & $\begin{array}{l}0.050 \\
(0.025-0.078)\end{array}$ & $\begin{array}{l}1.56^{* \mathrm{~b}} \\
(1.39-1.93)\end{array}$ \\
\hline & & & 7 & $1.32 \pm 0.19$ & $\begin{array}{l}0.030 \\
(0.013-0.050)\end{array}$ & $\begin{array}{l}2.53 * c \\
(2.28-3.60)\end{array}$ \\
\hline & \multirow{3}{*}{$0^{*}$} & \multirow{3}{*}{225} & 2 & $0.87 \pm 0.18$ & $\begin{array}{l}0.016 \\
(0.01-0.04)\end{array}$ & \\
\hline & & & 5 & $1.59 \pm 0.43$ & $\begin{array}{l}0.009 \\
(0.001-0.017)\end{array}$ & $\begin{array}{l}1.90 * \mathrm{~b} \\
(1.74-1.98)\end{array}$ \\
\hline & & & 7 & $1.66 \pm 0.50$ & $\begin{array}{l}0.007 \\
(0.001-0.016)\end{array}$ & $\begin{array}{l}2.20 * \mathrm{c} \\
(2.16-19.00)\end{array}$ \\
\hline \multirow{6}{*}{ Imidacloprid } & \multirow{3}{*}{ 우요 } & \multirow{3}{*}{250} & 2 & $4.40 \pm 0.59$ & $\begin{array}{l}0.023 \\
(0.021-0.027)\end{array}$ & \\
\hline & & & 5 & $4.16 \pm 0.53$ & $\begin{array}{l}0.019 \\
(0.017-0.021)\end{array}$ & $\begin{array}{l}1.06 * \mathrm{~b} \\
(1.05-1.14)\end{array}$ \\
\hline & & & 7 & $4.38 \pm 0.53$ & $\begin{array}{l}0.017 \\
(0.016-0.019)\end{array}$ & $\begin{array}{l}1.16 * \mathrm{c} \\
(1.12-1.27)\end{array}$ \\
\hline & \multirow{3}{*}{$0^{+}$} & \multirow{3}{*}{250} & 2 & $3.91 \pm 0.54$ & $\begin{array}{l}0.033 \\
(0.029-0.038)\end{array}$ & \\
\hline & & & 5 & $3.76 \pm 0.53$ & $\begin{array}{l}0.033 \\
(0.029-0.038)\end{array}$ & $\begin{array}{l}1.00^{\mathrm{b}} \\
(0.99-1.05)\end{array}$ \\
\hline & & & 7 & $3.57 \pm 0.52$ & $\begin{array}{l}0.033 \\
(0.029-0.038)\end{array}$ & $\begin{array}{l}1.00^{\mathrm{c}} \\
(0.99-1.01)\end{array}$ \\
\hline \multirow{6}{*}{ Acetamiprid } & \multirow{3}{*}{ 웅 } & \multirow{3}{*}{270} & 2 & $0.94 \pm 0.12$ & $\begin{array}{l}0.24 \\
(0.15-0.35)\end{array}$ & \\
\hline & & & 5 & $1.41 \pm 0.15$ & $\begin{array}{l}0.13 \\
(0.09-0.17)\end{array}$ & $\begin{array}{l}1.78^{* \mathrm{~b}} \\
(1.71-2.20)\end{array}$ \\
\hline & & & 7 & $1.61 \pm 0.17$ & $\begin{array}{l}0.11 \\
(0.07-0.17)\end{array}$ & $\begin{array}{l}2.20 * \mathrm{c} \\
(1.98-2.44)\end{array}$ \\
\hline & \multirow{3}{*}{$0^{+}$} & \multirow{3}{*}{270} & 2 & $2.93 \pm 0.39$ & $\begin{array}{l}0.68 \\
(0.55-0.83)\end{array}$ & \\
\hline & & & 5 & $4.36 \pm 0.80$ & $\begin{array}{l}0.59 \\
(0.50-0.69)\end{array}$ & $\begin{array}{l}1.09 * \mathrm{~b} \\
(1.03-1.15)\end{array}$ \\
\hline & & & 7 & $4.36 \pm 0.80$ & $\begin{array}{l}0.59 \\
(0.50-0.69)\end{array}$ & $\begin{array}{l}1.09 * \mathrm{c} \\
(1.03-1.15)\end{array}$ \\
\hline
\end{tabular}

Table 3. Toxicity response of Osmia cornifrons adults at different time intervals after pesticide treatment (2017). ${ }^{1}$ The product formulations are listed in Table S2. Quantal response regression lines are represented by slope \pm $\mathrm{SE}$ and $\mathrm{LD}_{50}$ (in $\mathrm{ng} \mathrm{AI} / \mathrm{mg}$ bodyweight). $\mathrm{LD}_{50}$ ratio in this table, or ratio of lethal concentrations causing $50 \%$ mortality at different time reading (in this table, $2 \mathrm{~d}$ vs $5 \mathrm{~d}$ or $2 \mathrm{~d}$ vs $7 \mathrm{~d}$ ), refers to the relative toxicity of a product at different time of reading compared with the standard $2 \mathrm{~d}$ reading proposed by EPA or EFSA ${ }^{4,10,11}$. A product significantly continues to cause mortality after $48 \mathrm{~h}$ post-exposure when the following requirements are met: (1) $\mathrm{LD}_{50}$ ratio $>1.0$, and (2) $95 \%$ limit of $\mathrm{LD}_{50}$ ratio does not include the value $1.0^{46}$. Otherwise, delayed mortality can be considered to not occur. Most $\mathrm{LD}_{50}$ ratios were $>1.0$, indicating that most of the chemicals continued to cause mortality after $48 \mathrm{~h}$. Products are listed in decreasing order, from the most to the least toxic (based on quantal

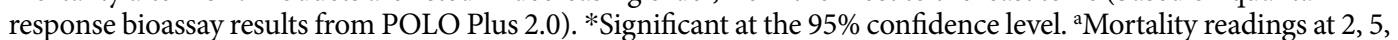
and $7 \mathrm{~d}$ after treatment. ${ }^{b} \mathrm{LD}_{50}$ at $2 \mathrm{~d}$ reading $\div \mathrm{LD}_{50}$ at $5 \mathrm{~d}$ reading. ${ }^{c} \mathrm{LD}_{50}$ at $2 \mathrm{~d}$ reading $\div \mathrm{LD}_{50}$ at $7 \mathrm{~d}$ reading.

temperatures until needed for experiments in February of 2016 and 2017. At that time, the overwintering, fully formed adults still in the cocoons were removed from refrigeration, then placed in $115 \mathrm{~mL}$ plastic cups at $20^{\circ} \mathrm{C}$ and allowed to emerge in insect cages (BugDorm-1 Insect Rearing Cage, MegaView Science Co. Ltd., Taiwan). To aid adult emergence from the cocoons, damp paper towels were lightly pressed onto the groups of loose cocoons in the plastic container to prevent movement of the cocoons which we found inhibited successful adult emergence, possibly due to lack of leverage for mandibles chewing through the tough cocoon. To further accelerate successful emergence, especially when large numbers of bees were needed to initiate an experiment, a small hole was made in the cocoon near the bee's head using a dissecting needle.

In a separate preliminary step to minimize variation in testing, 50 one-day-old adult bees of each sex were randomly selected from the cages and sorted by body weight. For all bioassays, we used females that represented weights between $100-110 \mathrm{mg}$ and males that represented weights between $65-75 \mathrm{mg}$. These weights approximate the mean of the weight distributions in the bee cohort (Fig. S2). Osmia adults were then caged into $250 \mathrm{~mL}$ plastic containers for pesticide toxicity assessment. Each container had five same-sex individuals, males and females were kept separately to measure sex differences (Fig. 2B). Additionally, we noted that if both sexes were caged in the same container, mating activities would take priority over feeding, which delayed the feeding process and affected the final results of the bioassay (NP and DB personal observation). 
$\mathbf{A}$

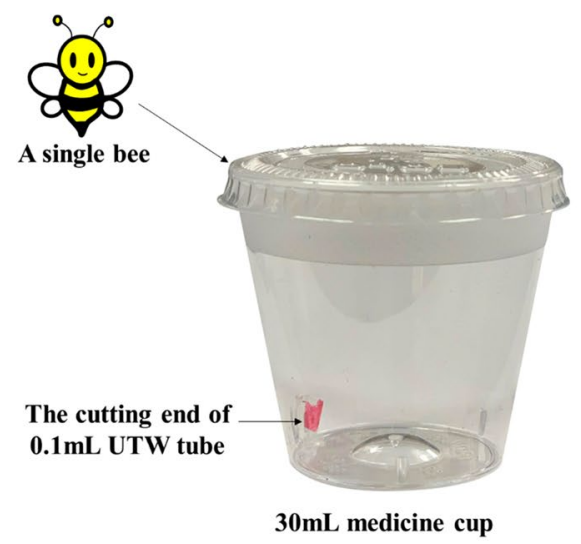

B

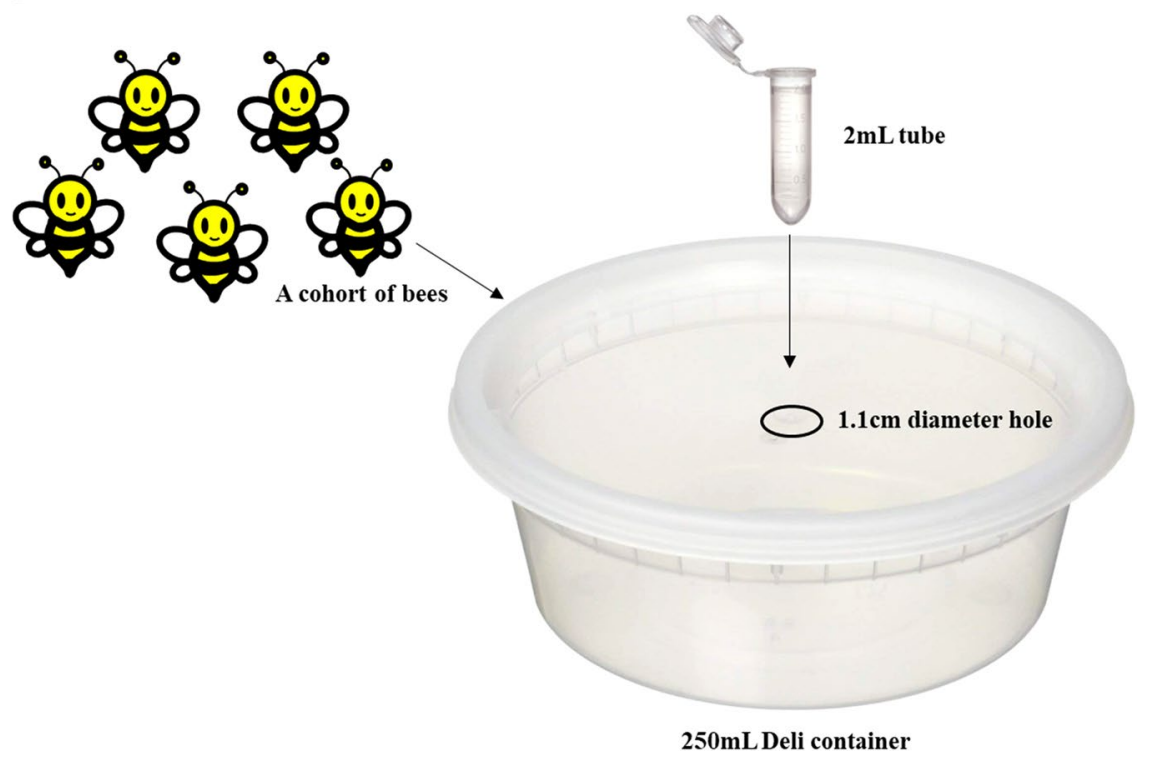

Figure 2. Feeding container design for Osmia cornifrons. (A) Individual feeding container; (B) Group feeding container.

Test of consumption per bee. In order to determine whether each bee consumed the same amount of food, we firstly carried out a consumption test by feeding bees individually and in groups of 5,10 , and 15 bees per container (Fig. 1). We chose 165 one-day-old bees of each sex that were within the selected weight range (100-110 mg for females, $65-75 \mathrm{mg}$ for males). The feeding solution was $50 \% \mathrm{~W}: \mathrm{W}$ sucrose solution. Bee weight was assessed before being caged and after consuming the assigned solution. The consumed amount per bee (in $\mathrm{mg}$ ) was the difference in a bee's weight before and after feeding, given that $O$. cornifrons did not defecate in the feeding container (NP personal observation).

Individual feeding method. For the individual feeding method, each bee was kept separately in a $30 \mathrm{~mL}$ plastic medicine cup with lid (Walgreens Co., Deerfield, IL). The feeder was made by cutting the bottom of a $0.1 \mathrm{~mL}$ UTW tube (ThermoFisher Scientific Inc., Waltham, MA), then attaching it to the corner of the container with a glue gun (Fig. 2A). Ten microliters of sugar water were delivered to each bee by pipette. We then placed three of these containers into a 500mL plastic 'Deli' container (Harvest Pack Gourmet Showcase, Minneapolis, MN) to keep the bees calm.

Group feeding method. For the group feeding method, O. cornifrons received treatments inside $250 \mathrm{~mL}$ plastic 'Deli' containers (Harvest Pack Gourmet Showcase, Minneapolis, MN). All sides of the containers were punched with $201 \mathrm{~mm}$-diameter holes to allow airflow. A small hole $(1.2 \mathrm{~cm}$ diameter $)$ was drilled in the lid to allow the introduction of live bees and extraction of dead bees. This hole was also used to attach a hanging feeder from the top. The feeder was a $2 \mathrm{~mL}$ clear polypropylene graduated centrifuge tube with snap cap and round bottom (Globe Scientific Inc., Mahwah, NJ) with several pin-sized holes at the side near the bottom to allow ad libitum feeding (Fig. 2B). Using this method, we evaluated a cohort of 5, 10, or 15 bees per container. All bees in group feeding were marked by number tags (Betterbee, Greenwich, NY) and their weights before and after feeding were 
recorded. We provided 50, 100, or $150 \mathrm{uL}$ sugar water to each group, respectively, in order to ensure bees received an average of $10 \mathrm{uL}$.

Ingestion bioassay protocol. Candidate pesticide concentrations were mixed with $50 \% \mathrm{~W}$ :W sucrose solution. At first, we dissolved the pesticides in water, and then we diluted this solution with sucrose solution to get the desired concentrations. Table S2 lists the insecticides used in this study. We selected the range of treatment concentrations based on a previously determined field-relevant concentration. Each pesticide was tested at $1 \times$, $3 \times, 10 \times, 30 \times, 100 \times$, etc., of the mean of the concentration found in nectar and pollen from previous work ${ }^{45}$. These field-relevant concentrations were the pesticide levels in apple nectar and pollen measured after typical field application rates applied using a commercial air-blast orchard sprayer at $1 \mathrm{~m}^{3}$ of water/hectare at the pink growth stage (approximately five days before bloom for the pesticide-resistant Rosy Apple Aphid) ${ }^{45}$. In order to generate a dose-mortality curve, we chose 5-6 different doses (each with three replicates of 15 bees/replicate) that caused 5-95\% mortality (after Robertson 2007) ${ }^{46}$.

For the ingestion bioassay, we maintained the bees, as described above for the consumption test, in groups of five bees per container. After 4 hours of starvation, the assigned treatment solution was fed to the group from the top of the containers. Bees were observed until they completely consumed the treatment solutions, then the treatment feeders were replaced with ad libitum $50 \% \mathrm{~W}: \mathrm{W}$ sucrose solution. Three replicates of bees (each replicate contained 3 groups of five) were tested for each treatment concentration, for a total of 45 bees per dose. Containers were kept at $25^{\circ} \mathrm{C}, \mathrm{RH} 70 \%$, with a photoperiod of 14:10 (L:D).

The plastic containers used to cage $O$. cornifrons were translucent to keep the bees calm. In clear containers, adult bees became agitated which affected their feeding (NP personal observation). In order to get the Osmia to accept the feeders, we either painted the feeder holes using a red Sharpie Permanent Marker (Newell Office Brands, NJ) (in 2016) or smears of honey (in 2017). In addition, we observed that the bees needed to defecate before they would feed, so they were left in the cages until they had defecated, then moved to the plastic containers.

Assessment of sex-based response to pesticides. From the results of the bee consumption experiment, to increase the probability of equal food consumption per bee for O. cornifrons, we separated five bees of the same sex into one group, and three groups of five bees were considered as one replication. All treatment and control solutions were completely consumed by the bees within 4 hours.

Delayed mortality assessment. In all experiments, mortality, which included dead and moribund bees, was recorded post-treatment at $12 \mathrm{~h}$ intervals for the first 48 hours and every $24 \mathrm{~h}$ after that until all bees were dead or 10 days had passed (after Biddinger 1998) ${ }^{47}$. Observed bees were divided into four main states: unaffected (no observable effects), weak (moving slowly); moribund (unable to move by themselves, trembling legs), and dead. Most of the weak bees recovered and moribund bees died subsequently. Bees were considered dead when they remained still during 30 s of observation ${ }^{48}$.

Statistical analysis. Quantal response regressions were conducted based on the response variables (states of bees) and explanatory variables (pesticide concentrations) with POLOPlus 2.0 (LeOra Software 2005) as described by Robertson $2007^{46}$. Regression lines represented the relationship between the response of bees and the concentration of pesticides, which allowed us to compare the toxicities of different pesticides by associating the concentrations that caused the same levels of mortality. $\mathrm{LC}_{50}$ (the concentration that kills $50 \%$ of the test population) values with $95 \% \mathrm{CI}$ were calculated by POLOPlus 2.0 using the probit model. The lethal dose $\left(\mathrm{LD}_{50}\right)$ of each pesticide to female and male O. cornifrons was calculated using the following formula:

$$
\left.L D_{50} \text { (in } \mathrm{ng} \mathrm{AI} / \mathrm{mg} \text { bodyweight }\right)=\frac{L C_{50}(\text { in } \mathrm{ng} \mathrm{AI} / \mathrm{uL} \text { dilution }) * 10 \mathrm{uL} \text { dilution }}{\text { Average body weight }(\text { in } \mathrm{mg})}
$$

\section{Data availability}

The datasets generated during the current study are available from the corresponding author on reasonable request.

Received: 8 November 2019; Accepted: 15 May 2020;

Published online: 11 June 2020

\section{References}

1. Biddinger, D. \& Rajotte, E. Integrated pest and pollinator management - Adding a new dimension to an accepted paradigm. Curr. Opin. Insect Sci. 10, 204-209 (2015).

2. Hooven, L., Sagili, R. \& Johansen, E. How to reduce bee poisoning from pesticides. (2013).

3. Hopwood, J. et al. Are neonicotinoids killing bees? A review of research into the effects of neonicotinoid insecticides on bees. Xerces Society for invertebrate conservation (The Xerces Society for Invertebrate Conservation, 2016).

4. OPP, PMRA \& CALDPR. Guidance for assessing pesticide risks to bees. (2014)

5. Kubik, M. et al. Pesticide residues in bee products collected from cherry trees protected during blooming period with contact and systemic fungicides. Apidologie 30, 521-532 (1999).

6. Bonmatin, J. et al. Environmental fate and exposure; neonicotinoids and fipronil. Environ. Sci. Pollut. Res. Int. 22, 35-67 (2015).

7. Simon-Delso, N. et al. Systemic insecticides (neonicotinoids and fipronil): Trends, uses, mode of action and metabolites. Environ. Sci. Pollut. Res. 22, 5-34 (2015).

8. Stanley, J. \& Preetha, G. Pesticide toxicity to pollinators: Exposure, toxicity and risk assessment methodologies. in Pesticide toxicity to non-target organisms 153-228 Springer. 10.1007/978-94-017-7752-0, (2016) 
9. Roubik, D. et al. The pollination of cultivated plants: A compendium for practitioners. Food And Agriculture Organization Of The United Nations (FAO) (Food and Agriculture Organization of The United Nations, 2018).

10. EFSA. Guidance on the risk assessment of plant protection products on bees (Apis mellifera, Bombus spp. and solitary bees). EFSA Journal 11, (European Food Safety Authority, 2013).

11. EPA. Guidance on exposure and effects testing for assessing risks to bees. (US Environmental Protection Agency, 2016).

12. Biddinger, D. et al. Comparative toxicities and synergism of apple orchard pesticides to Apis mellifera (L.) and Osmia cornifrons (Radoszkowski). PLoS One 8, 1-6 (2013).

13. Batra, S. W. T. The hornfaced bee for efficient pollination of small farm orchards. USDA Misc. Publ. 1422, 117-120 (1982).

14. Park, M. et al. Wild pollinators of Eastern apple orchards and how to conserve them. (Cornell University, Penn State University, and The Xerces Society. http://www.northeastipm.org/park2012, 2012)

15. Joshi, N. et al. Comparative trapping efficiency to characterize bee abundance, diversity, and community composition in apple orchards. Ann. Entomol. Soc. Am. 108, 785-799 (2015).

16. Batra, S. Hornfaced bees for apple pollination. Am. Bee J. 138, 361-365 (1998).

17. Vicens, N. \& Bosch, J. Pollinating efficacy of Osmia cornuta and Apis mellifera (Hymenoptera: Megachilidae, Apidae) on 'Red Delicious' apple. Environ. Entomol. 29, 235-240 (2000).

18. Matsumoto, S. \& Maejima, T. Several new aspects of the foraging behavior of Osmia cornifrons in an apple orchard. Psyche (Stuttg). 2010, 1-6 (2009).

19. Matsumoto, S., Abe, A. \& Maejima, T. Foraging behavior of Osmia cornifrons in an apple orchard. Sci. Hortic. (Amsterdam). 121, 73-79 (2009).

20. Biddinger, D. et al. An immunomarking method to determine the foraging patterns of Osmia cornifrons and resulting fruit set in a cherry orchard. Apidologie 44, 738-749 (2013).

21. Yamada, M., Oyama, N., Sekita, N., Shirasaki, S. \& Tsugawa, C. The ecology of the Megachilid bee Osmia cornifrons and its utilization for apple pollination. Bulletin of Aomori Experiment Station 15, (1971).

22. Sekita, N. \& Yamada, M. Use of Osmia cornifrons to pollinate apples in Aomori Prefecture, Japan. JARQ 26, 264-270 (1993).

23. Van der Steen, J. Review of the methods to determine the hazard and toxicity of pesticides to bumblebees. Apidologie 32, 399-406 (2001).

24. Ladurner, E., Bosch, J., Maini, S. \& Kemp, W. A method to feed individual bees (Hymenoptera: Apiformes) known amounts of pesticides. Apidologie 34, 597-602 (2003).

25. Ladurner, E., Bosch, J., Kemp, W. \& Maini, S. Evaluation of a standard artificial flower design to feed individual bees known amounts of pesticides. Apidologie 36, 379-387 (2005).

26. Marletto, F., Patetta, A. \& Manino, A. Laboratory assessment of pesticide toxicity to bumblebees. Bull. Insectology 56, 155-158 (2003).

27. Azpiazu, C. et al. Chronic oral exposure to field- realistic pesticide combinations via pollen and nectar: effects on feeding and thermal performance in a solitary bee. Sci. Rep. 9, 1-11 (2019).

28. Roessink, I. et al. A method for a solitary bee (Osmia sp.) first tier acute contact and oral laboratory test: An update. In Hazards of pesticides to bees - 13th international symposium of the ICP-PR Bee protection group 158. https://doi.org/10.5073/jka.2018.462.045 (2017)

29. Ladurner, E., Bosch, J., Kemp, W. \& Maini, S. Assessing delayed and acute toxicity of five formulated fungicides to Osmia lignaria Say and Apis mellifera. Apidologie 36, 449-460 (2005).

30. Abbott, V., Nadeau, J., Higo, H. \& Winston, M. Lethal and sublethal effects of imidacloprid on Osmia lignaria and clothianidin on Megachile rotundata (Hymenoptera: Megachilidae). J. Econ. Entomol. 101, 784-796 (2008).

31. Sgolastra, F. et al. Synergistic mortality between a neonicotinoid insecticide and an ergosterol-biosynthesis-inhibiting fungicide in three bee species. Pest Manag. Sci. 73, 1236-1243 (2017).

32. Gerber, H. \& Klostermeyer, E. Sex control by bees: A voluntary act of egg fertilization during oviposition. Science (80-.). 167, 82-84 (1970).

33. Bosch, J. \& Vicens, N. Relationship between body size, provisioning rate, longevity and reproductive success in females of the solitary bee Osmia cornuta. Behav. Ecol. Sociobiol. 60, 26-33 (2006).

34. Gallo, M. et al. General principles of Toxicology. in Casarett and Doull's: Toxicology - The Basic Science of Poisons (ed. Klaassen, C.) 1-107 (McGraw-Hill Medical Publishing Division. https://doi.org/10.1036/0071470514, 2008)

35. Cane, J., Sampson, B. \& Miller, S. Pollination value of male bees: The specialist bee Peponapis pruinosa (Apidae) at summer squash (Cucurbita pepo). Environ. Entomol. 40, 614-620 (2011).

36. Anderson, N. \& Harmon-Threatt, A. Chronic contact with realistic soil concentrations of imidacloprid affects the mass, immature development speed, and adult longevity of solitary bees. Sci. Rep. 9, 1-9 (2019).

37. Arena, M. \& Sgolastra, F. A meta-analysis comparing the sensitivity of bees to pesticides. Ecotoxicology 23, 324-334 (2014).

38. Manjon, C. et al. Unravelling the molecular determinants of bee sensitivity to neonicotinoid insecticides. Curr. Biol. 28, 1137-1143. e5 (2018)

39. Westerkamp, C. Honey bees are poor pollinators - why? Plant Syst. Evol. 177, 71-75 (1991).

40. Batra, S. Diversify will pollen bees. Am. Bee J. 134, 591-594 (1994).

41. Park, M. et al. Apple grower pollination practices and perceptions of alternative pollinators in New York and Pennsylvania. Renew. Agric. Food Syst. 1-14 (2018).

42. Peakall, R. \& Schiestl, F. A mark-recapture study of male Colletes cunicularius bees: Implications for pollination by sexual deception. Behav. Ecol. Sociobiol. 56, 579-584 (2004).

43. Ne'eman, G., Shavit, O., Shaltiel, L. \& Shmida, A. Foraging by male and female solitary bees with implications for pollination. J. Insect Behav. 19, 383-401 (2006).

44. Sapir, Y., Shmida, A. \& Ne'eman, G. Pollination of Oncocyclus irises (Iris: Iridaceae) by night-sheltering male bees. Plant Biol. 7 , 417-424 (2005)

45. Heller, S. et al. Pollinator exposure to systemic insecticides and fungicides applied in the previous fall and pre-bloom period in apple orchards. Environ. Pollut. https://doi.org/10.1016/j.envpol.2020.114589 (2020)

46. Robertson, J., Russel, R., Preisler, H. \& Savin, N. Bioassays with Arthropods. (CRC Press, 2007).

47. Biddinger, D., Hull, L. \& Rajotte, E. Stage specificity of various insecticides to tufted apple bud moth larvae (Lepidoptera: Tortricidae). J. Econ. Entomol. 91, 200-208 (1998).

48. Laurino, D., Manino, A., Patetta, A. \& Porporato, M. Toxicity of neonicotinoid insecticides on different honey bee genotypes. Bull. Insectology 66, 119-126 (2013).

\section{Acknowledgements}

This work was supported in part by a USDA-SCRI Research and Extension grant (PEN04398, D.J. Biddinger and E.G. Rajotte, PDs) on native pollinators, a USDA-NRCS Conservation Innovation grant with the Xerces Society for Invertebrate Conservation (D.J. Biddinger \& M. Vaughan, PDs), and by a USDA-NIFA Specialty Crop Research Initiative CAPS grant \#2012-51181-20105 (R. Isaacs, PD). N.J. was supported in part by the USDA NIFA (Hatch 1009954). N.P. is grateful for the administrative support provided by Assoc. Prof. Thai Pham 
(Research Center for Tropical Bees and Beekeeping, Vietnam National University of Agriculture). Authors are thankful to Prof. Gard Otis (University of Guelph, Canada) for constructive feedback and review of the previous draft of this paper and Sarah Heller, Dr. Julia Fine, Dr. Sulav Paudel (Penn State University), and all members of López-Uribe lab for valuable suggestions while conducting this study. Any opinions, findings, conclusions, or recommendations expressed in this publication are those of the authors and do not necessarily reflect the view of the U.S. Department of Agriculture or affiliated organizations.

\section{Author contributions}

D.B., N.P. and E.R. conceptualized and designed the study. N.P. conducted laboratory bioassays with inputs from D.B., E.R., N.J., M.L. and F.Z. N.P. analyzed the data generated in this study under the guidance of D.B., N.J., E.R. and M.L. N.P. and F.Z. developed visual graphics. N.P., D.B. and N.J. prepared the draft of this paper with contributions from E.R., M.L. and F.Z. All authors reviewed and approved the manuscript.

\section{Competing interests}

The authors declare no competing interests.

\section{Additional information}

Supplementary information is available for this paper at https://doi.org/10.1038/s41598-020-66118-2.

Correspondence and requests for materials should be addressed to N.T.P. or D.J.B.

Reprints and permissions information is available at www.nature.com/reprints.

Publisher's note Springer Nature remains neutral with regard to jurisdictional claims in published maps and institutional affiliations.

(c) (i) Open Access This article is licensed under a Creative Commons Attribution 4.0 International License, which permits use, sharing, adaptation, distribution and reproduction in any medium or format, as long as you give appropriate credit to the original author(s) and the source, provide a link to the Creative Commons license, and indicate if changes were made. The images or other third party material in this article are included in the article's Creative Commons license, unless indicated otherwise in a credit line to the material. If material is not included in the article's Creative Commons license and your intended use is not permitted by statutory regulation or exceeds the permitted use, you will need to obtain permission directly from the copyright holder. To view a copy of this license, visit http://creativecommons.org/licenses/by/4.0/.

(c) The Author(s) 2020 